\title{
eNOS and XRCC4 VNTR variants contribute to formation of nicotine dependence and/or schizophrenia
}

\author{
Pehlivan $\mathrm{S}^{1}$, Uysal $\mathrm{MA}^{2}$, Aydin $\mathrm{PC}^{3}$, Pehlivan $\mathrm{M}^{4}$, Nursal $\mathrm{AF}^{5}$, Yavuzlar $\mathrm{H}^{3}$, Kurnaz $\mathrm{S}^{1}$, Sever $\mathrm{U}^{1}$, \\ Yavuz FK², Uysal $\mathrm{S}^{2}$, Aydin $\mathrm{N}^{2}$
}

Department of Medical Biology, Istanbul University, Istanbul Faculty of Medicine, Istanbul, Turkey. sacide.pehlivan@istanbul.edu.tr

\begin{abstract}
BACKGROUND: This study aimed to evaluate whether VNTR variants in the Endothelial Nitric Oxide Synthase (eNOS) and the XRCC4 gene play any role in nicotine dependence (ND) and/or Schizophrenia+ND (Sch+ND) ethiopathogenesis.

METHODS: Present study included 100 individuals with ND, 60 patients with Sch+ND, and 70 healthy controls. These variants were analyzed using PCR.

RESULTS: The cases with ND had higher eNOS VNTR-BB genotype than the healthy control subjects $(p=$ 0.001 ). eNOS-AA genotype was lower in cases with Sch+ND and ND groups compared to the controls $(p=$ $0.001, p=0.001$, respectively). eNOS-B allele was found significantly more frequently in Sch+ND group compared to the controls $(p=0.001)$. eNOS-A allele was significantly lower in ND group than the controls $(p=0.001)$. XRCC4-ID genotype was more common in the ND group than the control group $(p=0.001)$ as heterozygosity disadvantage. XRCC4-DD genotype was more common in the Sch+ND group compared to the controls $(p=$ 0.035). The frequency of XRCC4-I allele was lower in the Sch+ND group compared to the controls $(p=0.012)$. CONCLUSIONS: Our results showed that eNOS and XRCC4 VNTR variants might play a potential role in Sch+ND and/or ND pathophysiology (Tab. 2, Ref. 48). Text in PDF www.elis.sk.

KEY WORDS: schizophrenia, endothelial nitric oxide synthase, XRCC4, nicotine dependence.
\end{abstract}

\section{Introduction}

Schizophrenia (Sch) is a complex psychiatric disorder, which affects approximately $1 \%$ of the general population (1). This disease is characterized by various symptoms and the prognosis and outcome of the disease differ among the patients (1). Until recently, ethiopathology of Sch has remained unclear. Distortions of several neurotransmitter systems, most notably the dopamine, glutamate, cholinergic, the serotonergic and the $\gamma$-aminobutyric acid (GABA) systems are believed to be crucial for the occurrence of this disease (2). Nicotine dependence (ND) is a serious public health issue leading to millions of preventable deaths worldwide.

Nitric oxide (NO) is a soluble, short-lived and freely diffusible gas, which has been reported to conduct numerous signaling tasks throughout the organism such as the central and peripheral nervous system (3). NO is produced after activation of glutamate

${ }^{1}$ Department of Medical Biology, Istanbul University, Istanbul Faculty of Medicine, Istanbul, Turkey, ${ }^{2}$ Department of Chest Diseases, Yedikule Hospital For Chest Diseases and Thoracic Surgery Training and Research Hospital, Istanbul, Turkey, ${ }^{3}$ Department of Psychiatry, Bakirkoy Research and Training Hospital for Psychiatry, Neurology and Neurosurgery, Istanbul, Turkey, ${ }^{4}$ Department of Haematology, Gaziantep Univesity, Faculty of Medicine, Gaziantep, Turkey, and ${ }^{5}$ Department of Medical Genetics, Hitit University, Faculty of Medicine, Corum, Turkey

Address for correspondence: S. Pehlivan, Prof, Dr, Istanbul University, Istanbul Faculty of Medicine

Department of Medical Biology, Capa-Fatih, Istanbul.

Phone: +90.212 .6351168$ receptors, mainly N-methyl-D aspatate (NMDA) subtype. NO is particularly crucial as the secondary messenger of NMDA receptor activation, which interacts with both dopaminergic and serotonergic pathways (4). Studies report evidence implying the role of NO in Sch. NO is synthesized from L-arginine by the enzyme nitric oxide synthase (NOS). Some studies reported that the high concentration of $\mathrm{NO}$ in cigarette smoke interferes with the action of enzyme NOS or lowers the level of NOS (5). In rats, NOS inhibitors can alleviate symptoms of the nicotine abstinence syndrome, and co-administration of L-arginine is likely to diminish the attenuating effect of the the NOS inhibitor (6). NOS has three distinct isoforms; neuronal (nNOS/NOS1), inducible (iNOS/NOS2) and endothelial (eNOS/NOS3) (7). eNOS involves mainly the endothelium, continuously producing NO and it helps to maintain basal vascular tone and cerebral blood flow. The eNOS gene located on chromosome 7q35-36 that has 26 exons that span $>21 \mathrm{~kb}$ of the genome encodes eNOS (GenBank D26607) (8). A variable number of tandem repeat (VNTR) (27 nt) in intron 4 of eNOS gene is responsible for production of more than $25 \%$ of basal plasma NO (9). It was established that this VNTR produces a small RNA (sirRNA from "short intronic repeat small RNA") inhibiting eNOS expression on the transcriptional level (10).

Several exogenous agents lead to DNA double-strand breaks (DSBs), which take place spontaneously during the cell cycle. DNA double-strand breaks (DSBs) are capable of destroying the integrity of the DNA molecule (11). DNA-repair process is crucial for the protection of the genome from environmental dam- 
age such as tobacco smoke. Evidence suggests that DNA repair is altered in chronic smokers. Furthermore, dysfunctional DNA damage repair process in patients with Sch has been discussed in numerous studies $(12,13)$. The gene encoding X-ray repair crosscomplementation group4 (XRCC4; OMIM: 194363) play a role in repair of DSBs (14). The protein encoded by XRCC4 is composed of 336 amino acid residues distributed among 8 exons, and has a long helical stem domain, which accounts for multimerization and interaction with DNA ligase IV (15). A VNTR variant exists in intron 3 of the XRCC4 gene.

In the present study, we aimed to find out whether the VNTR variants in eNOS and XRCC4 genes play any role in ND and/or $\mathrm{Sch}+\mathrm{ND}$ ethiopathogenesis.

\section{Patients and methods}

\section{Subjects}

This study included 100 individuals with ND (female/male: 46/54), 60 patients with Sch+ND (female/male: 45/15), and 70 healthy controls (female/male: $45 / 25$ ). The subjects were selected among the individuals from Bakirkoy Research and Training Hospital for Psychiatry Hospital, Istanbul Turkey and Yedikule Hospital For Chest Diseases and Thoracic Surgery Training and Research Hospital, Istanbul Turkey. Sch diagnosis was based on the DSM-IV-TR (Diagnostic and Statistical Manual of Mental Disorders, Fourth Edition, Text Revision) Criteria. The control group was selected from the voluntaries who did not have any psychological disorder and were non-smokers. Both the study and the control groups contained individuals of Turkish origin, and they were all over 18 years of age. Informed written consent was obtained from all patients and subjects before enrollment to the study, according to the ethical guidelines of the Declaration of Helsinki and the investigation was approved by the Instuitional Ethical Committee.

\section{Genotyping}

Genomic DNA was extracted from the whole blood treated with EDTA according to the established method (16). The extracted DNA was stored at $-20^{\circ} \mathrm{C}$ until analysis. eNOS (intron 4 VNTR $\mathrm{A} / \mathrm{B}$ ) and XRCC4 (intron 3 VNTR I/D) variants were genotyped by PCR described previously $(17,18)$ and agarose gel electro- phoresis. The experimental process was repeated twice for each sample. The distribution of the genotypes of patients and control subjects was compared.

\section{Statistical analysis}

All data were analyzed using software SPSS version 14.0 for Windows (SPSS Inc., Chicago, IL; USA). The statistical significance of the differences between the patient and control groups was estimated by logistic regression analysis. Odds ratio (OR) and $95 \%$ confidence interval $(\mathrm{CI})$ were also calculated. Differences in eNOS and XRCC4 VNTR genotype distribution between the patients and controls were compared with chi-square test and, Fisher's exact test was used when needed. The data were analyzed for appropriateness between the observed and expected genotypes as well as for Hardy-Weinberg Equilibrium (HWE). All analyses were two-tailed, and differences were interpreted as statistically significant when $\mathrm{p}<0.05$.

\section{Results}

A total number of 230 subjects from a Turkish population were recruited (100 ND, $60 \mathrm{Sch}+\mathrm{ND}$ and 70 healthy controls) in this study. The results of genotype distribution and allele frequency of eNOS VNTR variant in ND group, Sch+ND group versus controls are presented in the Table 1.

\section{eNOS genotyping}

A statistically significant difference in both the genotype distribution and allele frequency between cases and healthy controls was found for eNOS VNTR variant. The cases with ND had a higher frequency of eNOS VNTR BB genotype than the healthy control cases (OR: 4.218, 95\%Cl: 2.154-8.260; $\mathrm{p}=0.001$ ). Frequency of AA genotype was lower in cases of both Sch+ND group and ND group in comparison with the healthy controls, respectively (OR: 6.417, 95\% $\mathrm{Cl}: 2.067-19.923 ; \mathrm{p}=0.001$; OR: $14.819,95 \% \mathrm{Cl}$ : $4.225-51.978 ; \mathrm{p}=0.001$, respectively). B allele was found significantly more common in Sch+ND group compared to the controls (OR: $2.768,95 \% \mathrm{Cl}: 1.591-4.815 ; \mathrm{p}=0.001$ ). Frequency of A allele of eNOS VNTR was significantly lower in the ND group than the controls (OR: 5.342, 95\%Cl: 3.105-9.190; $\mathrm{p}=0.001)$.

Tab. 1. Comparison of eNOS VNTR variant between cases with Sch+ND, ND and control subjects.

\begin{tabular}{|c|c|c|c|c|c|c|}
\hline eNOS VNTR & $\mathrm{Sch}+\mathrm{ND}^{\mathrm{a}}$ & $\mathrm{ND}^{\mathrm{b}}$ & Controls & $\mathrm{OR}^{*}$ & $95 \% \mathrm{CI}^{*}$ & $\mathrm{p}$ \\
\hline Genotypes & $\mathrm{n}=60(\%)$ & $\mathrm{n}=100(\%)$ & $\mathrm{n}=70(\%)$ & & & \\
\hline $\mathrm{BB}$ & $39(65)$ & $79(79)$ & $33(47.1)$ & $\begin{array}{l}0.480^{\mathrm{a}} \\
4.218^{\mathrm{b}}\end{array}$ & $\begin{array}{l}0.237-0.974^{\mathrm{a}} \\
2.154-8.260^{\mathrm{b}}\end{array}$ & $\begin{array}{l}0.052^{\mathrm{a}} \\
0.001^{\mathrm{b}}\end{array}$ \\
\hline $\mathrm{AB}$ & $17(28.4)$ & $18(18)$ & $15(21.4)$ & $\begin{array}{l}0.690^{\mathrm{a}} \\
1.242^{\mathrm{b}}\end{array}$ & $\begin{array}{l}0.310-1.536^{\mathrm{a}} \\
0.578-2.672^{\mathrm{b}}\end{array}$ & $\begin{array}{l}0.417^{\mathrm{a}} \\
0.694^{\mathrm{b}}\end{array}$ \\
\hline AA & $4(6.6)$ & $3(3)$ & $22(31.5)$ & $\begin{array}{c}6.417^{\mathrm{a}} \\
14.819^{\mathrm{b}}\end{array}$ & $\begin{array}{l}2.067-19.923^{\mathrm{a}} \\
4.225-51.978^{\mathrm{b}}\end{array}$ & $\begin{array}{l}0.001^{\mathrm{a}} \\
0.001^{\mathrm{b}}\end{array}$ \\
\hline \multicolumn{7}{|l|}{ Alleles } \\
\hline$\overline{\mathrm{B}}$ & $95(79.2)$ & $176(88)$ & $81(57.8)$ & $2.768^{\mathrm{a}}$ & $1.591-4.815^{\mathrm{a}}$ & $0.001^{\mathrm{a}}$ \\
\hline A & $25(20.8)$ & $24(12)$ & $59(42.2)$ & $5.342^{b}$ & $3.105-9.190^{\mathrm{b}}$ & $0.001^{\mathrm{b}}$ \\
\hline HWEp & 0.2745 & 0.1396 & 2.730 & & & \\
\hline
\end{tabular}

Fisher's Exact Test, a comparison of genotype frequencies between Sch+ND and healthy control groups; ${ }^{\mathrm{b}}$ comparison of genotype frequencies between ND and healthy control groups. HWEp: Hardy Weinberg Equliibrium. 
Tab. 2. Comparison of XRCC4 VNTR variant between patients with Sch+ND, ND and healthy control subjects.

\begin{tabular}{|c|c|c|c|c|c|c|}
\hline XRCC4 VNTR & $\mathrm{Sch}+\mathrm{ND}$ & ND & Controls & $\mathrm{OR}^{*}$ & $95 \% \mathrm{CI}^{*}$ & $\mathrm{p}$ \\
\hline Genotypes & $\mathrm{n}=48(\%)$ & $\mathrm{n}=103(\%)$ & $\mathrm{n}=69(\%)$ & & & \\
\hline II & $13(27)$ & $21(20)$ & $24(35)$ & $\begin{array}{l}1.846^{\mathrm{a}} \\
2.083^{\mathrm{b}}\end{array}$ & $\begin{array}{l}0.837-4.073^{\mathrm{a}} \\
1.045-4.149^{\mathrm{b}}\end{array}$ & $\begin{array}{l}0.170^{\mathrm{a}} \\
0.051^{\mathrm{b}}\end{array}$ \\
\hline ID & $11(23)$ & $55(54)$ & $19(42)$ & $\begin{array}{l}1.624^{\mathrm{a}} \\
0.332^{\mathrm{b}} \\
\end{array}$ & $\begin{array}{l}0.699-3.771^{\mathrm{a}} \\
0.172-0.638^{\mathrm{b}}\end{array}$ & $\begin{array}{l}0.299^{\mathrm{a}} \\
0.001^{\mathrm{b}} \\
\end{array}$ \\
\hline DD & $24(50)$ & $27(26)$ & $16(23)$ & $\begin{array}{l}0.428^{a} \\
0.850^{b}\end{array}$ & $\begin{array}{l}0.199-0.919^{\mathrm{a}} \\
0.417-1.730^{\mathrm{b}}\end{array}$ & $\begin{array}{l}0.035^{\mathrm{a}} \\
0.721^{\mathrm{b}}\end{array}$ \\
\hline \multicolumn{7}{|l|}{ Alleles } \\
\hline I & 37 (39) & $97(47)$ & $77(56)$ & $2.013^{a}$ & $1.184-3.423^{\mathrm{a}}$ & $0.012^{\mathrm{a}}$ \\
\hline $\mathrm{D}$ & $59(61)$ & $109(53)$ & $61(44)$ & $1.418^{b}$ & $0.920-2.188^{b}$ & $0.124^{\mathrm{b}}$ \\
\hline HWEp & 0.000 & 0.467 & 0.008 & & & \\
\hline
\end{tabular}

Fisher's Exact Test, ${ }^{\text {a }}$ comparison of genotype frequencies between Sch+ ND and healthy control groups; ${ }^{b}$ comparison of genotype frequencies between ND and healthy control groups. HWEp: Hardy Weinberg Equliibrium.

\section{XRCC4 genotyping}

Genotype and allele frequencies of XRCC4 gene intron 3 VNTR variant are shown in the Table 2. There was a significant difference for genotype distribution and allele frequency of VNTR variant of $\mathrm{XRCC} 4$ gene between groups. XRCC4 ID genotype was more common in ND group than in controls (OR: $0.332,95 \% \mathrm{Cl}$ : 0.172-0.638; $\mathrm{p}=0.001)$. The cases with $\mathrm{Sch}+\mathrm{ND}$ had a higher DD genotype than healthy control group (OR: $0.428,95 \% \mathrm{Cl}$ : 0.417-1.730; $\mathrm{p}$ $=0.035)$. Frequency of XRCC4 VNTR variant I allele was lower in the Sch+ND group compared to the healthy group (OR: 2.013, 95\% $\mathrm{Cl}$ : $1.184-3.423 ; \mathrm{p}=0.012$ ).

\section{Discussion}

Sch is a severe psychiatric disease with a chronic course, mostly occurring at a young age. Genetic factors are involved in up to $80 \%$ of cases with Sch (1). Cigarette smoking can be regarded as an easy and common way to receive multiple doses of psychoactive drug nicotine (1). Besides, smoking results in ND and it is the most significant cause of preventable death. There are more than 4000 components in cigarette smoke, but the pharmacological impacts of dependence are primarily due to nicotine, which acts through neuronal nicotinic acetylcholine receptors (nAChRs). It was shown that acute and chronic nicotine administration to rats elevates the levels of stable metabolites of NO in various brain regions (19). The apparently high prevalence of smoking among the patients with Sch indicates the possibility that the common co-occurrence of nicotine use and Sch can be associated with mutual underlying neurobiological factors (20). Several studies showed that NO may act in the pathogenesis of many psychiatric diseases, including depression (21), bipolar disorder (22), and Sch $(23,24)$. Nakano et al (25) suggested that plasma levels of NO and its metabolites are diminished in patients with Sch and they reported that the baseline plasma NO metabolites levels were significantly lower in the Sch group. Arinole et al (26) showed that plasma NO level was significantly elevated in drug free patients with Sch compared to the controls or treated patients in a Nigerian cohort.

The eNOS 27-bp VNTR variant in intron 4 possesses two common alleles: 4 repeats and 5 repeats. Two less common alleles were found (with 6 and 3 repeats) in African and Colombian populations
(27). Some studies suggest that carriers of 4 repeat allele have decreased NO plasma levels and diminished protein expression; however, there is a controversy among the various studies. The variant is probably in linkage disequilibrium with other functional variants in regulatory regions of the eNOS gene (27). The biological influence of the eNOS VNTR variant remains unclear, however it was implied that this variant modulates the expression of eNOS by the production of sirRNAs. Human eNOS is expressed in the cerebral endothelial cells throughout the brain and its mRNA is also expressed in several regions of basal ganglia such as caudate nucleus, putamen, substantia nigra and subthalamicc nucleus (28). The impaired expression of eNOS was believed to be major abnormality common to neurodegenerative diseases. Previously, it was reported that nNOS $276 \mathrm{C}+$ genotype incidence was significantly higher in the patients with obsessive-compulsive disorder than the controls (29). Also, the genotype distribution of the variants in exon 22 of the iNOSA gene and in exon 29 of the nNOS gene were significantly different between the patients with recurrent depressive disorder and the control cases (30). Reif et al (31) showed that the eNOS genotype might bear a modest genetic risk of developing bipolar disorder. Also, it was shown that three eNOS variants were not significantly different in depressed Japanese patients (32). On the other hand, Zeman et al (33) reported that the eNOS genotype (rs1979983) was not associated with depression. The analysis of the mini-haplotype of nNOS showed a crucial relation with Sch, and single-marker association analysis revealed that the exon 1c promoter variant was related to $\mathrm{Sch}$, indicating that regulatory rather than coding variants of nNOS act as a genetic risk factor for Sch (34). Furthermore, Shinkai et al (35) found that the variant, a CT transition located $276 \mathrm{bp}$ downstream from the translation termination site, described in exon 29 of human nNOS gene, was significantly related with Sch, indicating that the nNOS gene involves in the pathophysiology of Sch. Okumura et al (36) found that two variants (rs3782219 and rs3782206) of nNOS gene showed a significant association with Sch in allele and/or genotype-wise analysis.

In this study, we tested the hypothesis that VNTR variants of eNOS/XRCC4 might influence the development of ND and/or $\mathrm{Sch}+\mathrm{ND}$. We found that the cases with ND had a higher eNOS VNTR BB genotype than healthy control $(\mathrm{p}=0.001)$ (Tab. 1). Also, $\mathrm{B}$ allele was found in a significantly higher frequency in Sch $+\mathrm{ND}$ 
group compared to controls $(\mathrm{p}=0.001)$. Frequency of A allele of eNOS VNTR was significantly lower in the ND group than in the control group $(p=0.001)$. These results supported the idea that eNOS VNTR AA genotype and A allele had a protective effect on the risk of Sch/ND and ND.

DNA damage can either arise from exposure to exogenous DNA damaging agents like tobacco smoke or UV radiation, endogenous sources such as oxidative stress originating from the respiratory chain, or it can be due to decrease in repair of normal levels of DNA damage continuously occurring in our genomes $(11,37)$. Tobacco smoke has numerous potent chemical carcinogens such as polycyclic aromatic hydrocarbons (PAHs), aromatic amines and $\mathrm{N}$-nitroso compounds. These carcinogens may cause direct and indirect DNA damage. Several types of DNA damage are repaired through multiple repair pathways where numerous proteins take a part. DNA-repair process is very important for the protection of the genome from environmental damage including tobacco smoke. Nucleotide excision repair pathway concerns with DNA damage created by the tobacco-related carcinogen benzo(a) pyrene, while base excision repair pathway repairs DNA damage created by reactive oxygen species resulting from cigarette smoke (37). The signs of enhanced oxidative stress and oxidative DNA damage were found in different tissues of the patients with Sch (38). The mutagens sensitivity and efficacy of DNA repair are affected by variation in many genes such as XRCC genes.

A nuclear phoshoprotein is encoded and multimerized by XRCC4 gene. XRCC4 also interacts with DNA Ligase4 and DNAdependent protein kinase, involving in the non-homologous end joining (NHEJ) pathway (39). In mice, XRCC4-deficiency leads to massive neuronal apoptosis hence it is embryo-lethal condition. XRCC4 was reported to interact with p53 in the modulation of apoptosis, implying that XRCC4 is essential for maintaining genomic stability and for the suppression of tumors (40). DNArepairing gene variations might affect genomic instability as well as influencing protein function and growth intervention. Numerous studies have associated the variants in DNA repair genes to the occurrence of Sch. The observation of high smoking prevalence among Sch patients (the rate of smoking among the patients with Sch has been reported to be at least three to five times more than in the general population) gives rise to thought that ND could be an etiological factor for this disease. There are many studies that investigated the association between XRCC gene variants and cancer (41), preeclampsia (42), ulcerative colitis (43), and rheumatoid arthritis (44). Saadat et al (45) showed that the 399Gln allele in exon 10 variant of XRCC1 gene had in increased the risk of Sch. However, it was reported that there was no association between Arg194Trp variant of XRCC1 gene and Sch in the same population (46). Also, it was reported that XRCC1 gene (Arg399Gln) variant Gln399Gln genotype was associated with Sch in South Indian population (47). Odemis et al (48) showed that XRCC1 (Gln) and XRCC3 (Thr) alleles were significantly more frequent among the patients with Sch than the controls.

In the present study, we found that XRCC4 ID genotype was more common in ND group than in the controls $(\mathrm{p}=0.001)$. Besides, it was found that XRCC4 VNTR DD genotype was more common in the Sch+ND group compared to the control group (p $=0.001$ ). The present study is the first research in literature, which demonstrated that DD genotype was associated with susceptibility to Sch and presence of ID genotype had a role as "heterozygosity disadvantage for ND" in Turkish population. It was found that the frequency of XRCC4 I allele was lower in the Sch+ND group than in the control group $(p=0.012)$. It is possible that XRCC4 I allel can play a role in protecting from this disease.

To our knowledge, the present study is the first report showing a significant association between eNOS/XRCC4 VNTR variants and ND and/or Sch+ND in a Turkish cohort. Our results showed that eNOS/XRCC4 VNTR variants constitute a risk factor for both ND and Sch+ND ethiopathogenesis. However, large-scale studies should be replicated with different subjects and/or other ethnic groups to fully elucidate the effects of these variants on susceptibility to ND and/or Sch+ND.

\section{References}

1. Reed AC, Harris JG, Olincy A. Schizophrenia, smoking status, and performance on the matrics Cognitive Consensus Battery. Psychiatry Research 2016 ; 246: 1-8.

2. Steeds H, Carhart-Harris RL, Stone JM. Drug models of schizophrenia. Ther Adv Psychopharmacol 2015; 5 (1): 43-58.

3. Siragusa M, Fleming I. The eNOS signalosome and its link to endothelial dysfunction. Eur J Physiol 2016; 468 (7): 1125-1137.

4. Lorrain DS, Hull EM. Nitric oxide increases dopamine and serotonin release in the medial preoptic area. Neuroreport 1993; 5 (1): 87-89.

5. Robbins RA, Millatmal T, Lassi K, Rennard S, Daughton D. Smoking cessation is associated with an increase in exhaled nitric oxide. Chest 1997; 112 (2): 313-318.

6. Malin DH, Lake JR, Shenoi M et al. The nitric oxide synthesis inhibitor nitro-L-arginine (L-NNA) attenuates nicotine abstinence syndrome in the rat. Psychopharmacology (Berl) 1998; 140 (3): 371-377.

7. Wang XL, Wang J. Endothelial nitric oxide synthase gene sequence variations and vascular disease. Mol Genet Metab 2000; 70 (4): 241-251.

8. Hu H, Huang Y, Jiang L et al. Relationship between eNOS gene polymorphism and cerebral infarction of young and middle-aged Chinese Han population. Bratisl Lek Listy 2014; 115 (11): 708-711.

9. Wang XL, Mahaney MC, Sim AS et al. Genetic contribution of the endothelial constitutive nitric oxide synthase gene to plasma nitric oxide levels. Arterioscler Thromb Vasc Biol 1997; 17 (11): 3147-3153.

10. Babushkina NP, Kucher AN. Functional role of VNTR polymorphism of human genes. Rus J Genet 2011; 47 (6): 637-645.

11. Lescale C, Lenden Hasse H, Blackford AN et al. Spesific roles of XRCC4 paralogs and XLF during recombination. Cell Rep 2016; 16 (11): 2967-2979.

12. Psimadas D, Messini-Nikolaki N, Zafiropoulou M, Fortos A, Tsilimigaki S, Piperakis SM. DNA damage and repair efficiency in lymphocytes from schizophrenic patients. Cancer Lett 2004; 204 (1): 33-40.

13. Shiwaku H, Okazawa H. Impaired DNA damage repair as a common feature of neurodegenerative diseases and psychiatric disorders. Curr Mol Med 2015; 15 (2): 119-128.

14. Li Z, Otevrel T, Gao Y et al. The XRCC4 gene encodes a novel protein involved in DNA double-strand break repair and recombination. Cell 1995; 83 (7): 1079-1089. 
15. Shao N, Jiang WY, Qiao D et al. An updated meta-analysis of XRCC4 polymorphisms and cancer risk based on 31 case-control studies. Cancer Biomark 2012-2013; 12 (1): 37-47.

16. Miller SA, Dykes DD, Polesky HF. A simple salting out procedure for extracting DNA from human nucleated cells. Nucleic Acids Res 1988; 16 (3): 1215.

17. Safarinejad MR, Safarinejad S, Shafiei N, Safarinejad S. Effects of the T-786C, G894T, and intron 4 VNTR (4a/b) polymorphisms of the endothelial nitric oxide synthase gene on the risk of prostate cancer. Urol Oncol 2013; 31 (7): 1132-1140.

18. Cifci S, Yilmaz M, Pehlivan M, Sever T, Okan V, Pehlivan S. DNA repair genes polymorphisms in multiple myeloma: no association with XRCC1 (Arg399Gln) polymorphism, but the XRCC4 (VNTR in intron 3 and G1394T) and XPD (Lys751 Gln) polymorphisms is associated with the disease in Turkish patients. Hematology 2011; 16 (6): 361-367.

19. Pogun S, Demirgoren S, Taskiran $D$ et al. Nicotine modulates nitric oxide in rat brain. Eur Neuropsychopharmacol 2000; 10 (6): 463-472.

20. Besson M, Forget B. Cognitive dysfunction, affective states, and vulnerability to nicotine addiction: A multifactorial perspective. Frontiers in Psychiatry 2016; 7: 160.

21. Kim YK, Paik JW, Lee SW, Yoon D, Han C, Lee BH. Increased plasma nitric oxide level associated with suicide attempt in depressive patients. Prog Neuropsychopharmacol Biol Psychiatry 2006; 30 (6): 1091-1096.

22. Andreazza AC, Kauer-Sant'anna M, Frey BN et al. Oxidative stress markers in bipolar disorder: a meta-analysis. J Affect Disord 2008; 111 (2-3): 135-144.

23. Akbarian S, Bunney WE Jr, Potkin SG et al. Altered distribution of nicotinamide-adenine dinucleotide phosphate-diaphorase cells in frontal lobe of schizophrenics implies disturbances of cortical development. Arch Gen Psychiatry 1993; 50 (3): 169-177.

24. Cui H, Nishiguchi N, Yanagi M et al. A putative cis-acting polymorphism in the NOS1 gene is associated with schizophrenia and NOS1 immunoreactivity in the postmortem brain. Schizophr Res 2010; 121 (1-3): 172-178.

25. Nakano Y, Yoshimura R, Nakano H et al. Association between plasma nitric oxide metabolites levels and negative symptoms of schizophrenia: a pilot study. Hum Psychopharmacol 2010; 25 (2): 139-144.

26. Arinola O, Idonije $\mathbf{O}$. Status of plasma nitric oxide and non-enzymatic antioxidants before and after antipsychotic treatment in Nigerian patients with schizophrenia. J Res Med Sci 2009; 14 (1): 37-42.

27. Ramírez-Patiño R, Figuera LE, Puebla-Pérez AM et al. Intron 4 VNTR (4a/b) polymorphism of the endothelial nitric oxide synthase gene is associated with breast cancer in Mexican women. J Korean Med Sci 2013; 28 (11): 1587-1594.

28. Liou YJ, Lai IC, Lin M et al. Haplotype analysis of endothelial nitric oxide synthase (NOS3) genetic variants and tardive dyskinesia in patients with schizophrenia. Pharmacogenet Genomics 2006; 16: 151-57.

29. Topaloglu M, Tuzun E, Gulec H, Bireller ES, Cakmakoglu B, Kucukali CI. Neuronal nitric oxide synthase polymorphisms in obsessive-compulsive disorder. Nord J Psychiatry 2017; 71 (2): 115-119.

30. Galecki P, Maes M, Florkowski A et al. Association between inducible and neuronal nitric oxide synthase polymorphisms and recurrent depressive disorder. J Affect Disord 2011; 129 (1-3): 175-182.

31. Reif A, Strobel A, Jacob CP et al. A NOS-III haplotype that includes functional polymorphisms is associated with bipolar disorder. Int J Neuropsychopharmacol 2006; 9 (1): 13-20.

32. Ikenouchi-Sugita A, Yoshimura R, Kishi $\mathbf{T}$ et al. Three polymorphisms of the eNOS gene and plasma levels of metabolites of nitric oxide in depressed Japanese patients: a preliminary report. Hum Psychopharmacol 2011; 26 (7): 531-534.

33. Zeman M, Jáchymová M, Jirák R et al. Polymorphisms of genes for brain-derived neurotrophic factor, methylenetetrahydrofolate reductase, tyrosine hydroxylase, and endothelial nitric oxide synthase in depression and metabolic syndrome. Folia Biol (Praha) 2010; 56 (1): 19-26.

34. Reif A, Herterich S, Strobel A et al. A neuronal nitric oxide synthase (NOS-I) haplotype associated with schizophrenia modifies prefrontal cortex function. Mol Psychiatry 2006; 11 (3): 286-300.

35. Shinkai T, Ohmori O, Hori H, Nakamura J. Allelic association of the neuronal nitric oxide synthase (NOS1) gene with schizophrenia. Mol Psychiatry 2002; 7 (6): 60-63.

36. Okumura T, Okochi T, Kishi T et al. No association between polymorphisms of neuronal oxide synthase 1 gene (NOS1) and schizophrenia in a Japanese population. Neuromol Med 2009; 11 (2): 123-127.

37. Alexandrov LB, Ju YS, Haase K et al. Mutational signatures associated with tobacco smoking in human cancer. Science 2016; 354 (6312): 618-623.

38. Sirota $\mathbf{P}$, Gavrieli R, Wolach B. Overproduction of neutrophil radical oxygen species correlates with negative symptoms in schizophrenic patients: parallel studies on neutrophil chemotaxis, superoxide production and bactericidal activity. Psychiatry Res 2003; 121 (2): 123-132.

39. Hayden PJ, Tewari P, Morris DW et al. Variation in DNA repair genes XRCC3, XRCC4, XRCC5 and susceptibility to myeloma. Hum Mol Genet 2007; 16 (24): 3117-3127.

40. Gao Y, Ferguson DO, Xie W et al. Interplay of p53 and DNA-repair protein XRCC4 in tumorigenesis, genomic stability and development. Nature 2000; 404 (6780): 897-900.

41. Rybicki BA, Conti DV, Moreira A, Cicek M, Casey G, Witte JS. DNA repair gene XRCC1 and XPD polymorphisms and risk of prostate cancer. Cancer Epidemiol Biomarkers Prev 2004; 13 (1): 23-29.

42. Sandoval-Carrillo A, Méndez-Hernández EM, Vazquez-Alaniz F et al. Polymorphisms in DNA repair genes (APEX1, XPD, XRCC1 and $\mathrm{XRCC} 3$ ) and risk of preeclampsia in a Mexican mestizo population. Int $\mathrm{J}$ Mol Sci 2014; 15 (3): 4273-4283.

43. Bardia A, Tiwari SK, Gunisetty $S$ et al. Functional polymorphisms in XRCC-1 and APE-1 contribute to increased apoptosis and risk of ulcerative colitis. Inflamm Res 2012; 61 (4): 359-365.

44. Pehlivan S, Balci SO, Aydeniz A, Pehlivan M, Sever T, Gursoy S. Might there be a link between intron 3 VNTR polymorphism in the XRCC4 DNA repair gene and the etiopathogenesis of rheumatoid arthritis? Genet Test Mol Biomarkers 2015; 19 (1): 48-51.

45. Saadat M, Pakyari N, Farrashbandi H. Genetic polymorphism in the DNA repair gene XRCC1 and susceptibility to schizophrenia. Psychiatry Res 2008; 157 (1-3): 241-245.

46. Derakhshandeh S, Saadat I, Farrashbandi H, Saadat M. Association between genetic polymorphism of XRCC1 Arg194Trp and risk of schizophrenia. Psychiatry Res 2009; 169 (2): 186.

47. Sujitha SP, Kumar DT, Doss CG et al. DNA Repair Gene (XRCC1) Polymorphism (Arg399Gln) Associated with Schizophrenia in South Indian Population: A Genotypic and Molecular Dynamics Study. PLoS One 2016; 11 (1): $\mathrm{e} 0147348$.

48. Odemis $\mathrm{S}$, Tuzun E, Gulec $\mathrm{H}$ et al. Association between polymorphisms of DNA repair genes and risk of schizophrenia. Genet Test Mol. Biomark 2015; 20 (1): 11-17.

Received March 10, 2017. Accepted April 6, 2017. 